\title{
Poor Performance Status
}

National Cancer Institute

\section{Source}

National Cancer Institute. Poor Performance Status. NCI Thesaurus. Code C115331.

Performance status defined as poor according to the ECOG performance score or Karnofsky performance score. 